\title{
Island of Glass
}

"Glass is more gentle, graceful, and noble than any metal and its use of more delightful, polite, and sightly than any other material at this day known to the world." Those were the words of Antonio Neri whose 1612 technical book, The Art of Glass, accelerated the diffusion of some of Europe's greatest glass-making secrets from the Venetian island of Murano.

Murano is about an hour's gondola ride from Venice. Like Venice, Murano consists of smaller islands separated by lagoons but interconnected by bridges. Running from north to south on Murano in the direction of Venice is the Rio dei Vetraithe glassmaker's canal. It is a place where the fires of the glass-making furnaces have raged now for more than 700 years. During the centuries of the Renaissance, Murano's master glass-makers on this canal achieved some of the most important breakthroughs in the history of glassmaking. Yet early in the 14th century, Venetian merchant ships laden with glass goblets, wineglasses, beakers, bowls, and other items already were sailing for their Mediterranean home base to distant ports.

Murano became the official hub of Venetian glassmaking in 1291 when Venetian authorities, who ruled with micromanagerial fervor, decreed that all glass-making furnaces in Venice itself had to be shut down and their operation reestablished on Murano. Historians point to two reasons for moving the industry, which by 1291 already had been present in the city for at least 300 years. The official reason for the move was to reduce the city's vulnerability to fire, which had punctuated the city's history like a recurring plague.

However, there was also a hidden agenda. By sequestering the 3,000 or so glassmakers on Murano, the Venetian authorities could exercise a more iron-handed control over them while better protecting the artisans' hard-won technical knowhow and manufacturing secrets. The Venetians had reason to be paranoid since their city was the emporium of Europe, a place where people from all over the world came to trade goods and exchange ideas. Some came to steal industrial secrets.

Particularly during the 15th and 16th centuries, the glassmakers' proprietary information was the basis of considerable income to the materialistic culture that was Venice. Later in the Renaissance, when Venice's grip on the European glass-making market began to slip seriously (and Neri's book didn't help them any), glassmakers who left the island without securing permission from authorities risked death at the hands of professional assassins.

Despite restrictions on their lifestyle, the Muranese glassmakers raised their art to levels the world had never known. Just as today, the major ingredients of their glass were silica and an alkali flux, known as fondente to the Muranese glassmakers, an agent that reduces the temperature at which the silica fuses into a glassy mass. One reason for the superiority of Muranese glass products was the care they took to use only those ingredients that experience had shown them would lead to good results. A preferred source of silica, the major ingredient of glass, were white stones harvested from the Ticino River. Stones from other sources were prone to introduce unwanted color, such as yellow, into the product. The best flux came from ash imported from the coasts of Syria and Alexandria, from which glassmaking might have first arrived in Venice, where the source of the ash were plants rich in sodium. Renaissance glassmakers in northern Europe could not compete with the Muranese, in part, because the ash they prepared had less pure alkali from their local plants.

In the 15th century, one of Murano's best-known glassmakers, Angelo Barovier, attended lessons by the philosopher-scientist Paolo da Pergola, who also was an alchemist and therefore was likely to be obsessed with purifying ingredients. With Paolo's influence, Angelo Barovier worked out a purification process for the fondente. First he sifted the raw soda ash to exclude large particles and other detritus. After dissolving the sifted powder in hot water, he decanted the liquid and then filtered the liquid from any remaining solid residue. Finally, he evaporated the water to yield a crystalline product known as glass salts.

Angelo Barovier used this purified material as the flux. When he combined it with the silica from the Ticino River's quartz pebbles and a mineral, which he referred to as magnesium of Piedmonte, whose decolorizing property was common knowledge among the Muranese glassmakers, he had the basic formula for what would prove to be a revolutionary product. So colorless and clear was the glass Barovier produced that it resembled rock crystal. It became known as cristallo. The new material was also exceptionally workable, opening up new creative possibilities for Barovier and other glass masters. Muranese mirrors would become coveted throughout the world for their exceptional clarity and the availability of glass for windows would enable Venice's architects to bring more light into their building than was possible in most other places.

By the end of the 15th century, the secret of cristallo spread throughout the best glasshouses of Murano. According to a detailed guide for the Murano Glass Museum, "Murano glass of this period was greatly appreciated throughout Europe and was used for adorning the houses of the nobility and of rich bourgeois families who frequently ordered supplies direct from the island's principal workshops." Besides the makers of glass itself, the island had enamelers, gilding specialists, diamond-point engravers, and all manner of artists to embellish the material with great skill and variety. So fine were the best Muranese glass vessels that some paranoid members of the upper class in this conspiracy-riddled society believed the glass would shatter if poison were to touch it.

In addition to Barovier's 15th century breakthrough with cristallo, other Muranese artisans were pushing the envelope with such innovations as lattimo. This material innovation was roughly contemporary with Barovier's invention of cristallo. Its initial production may have been inspired by an influx of Chinese porcelain. In 1527, the Serena Glassworks, run by Filippo and Bernardo Catani, put several of these advances together in their invention of filigree glass marked by intricate lacy designs. They made such objects by infiltrating cristallo with twisted patterns of thin lattimo initially worked into the hot glass as thin threads.

Throughout the 16th century, more and more Muranese artisans emigrated illegally, seeding many other places with glassmaking expertise. The Venetian monopoly in art glass began to give way. Yet glassmaking was then already too deeply rooted in Muranese culture ever to leave. Even today, some of the island's glassmakers are descendants of artisans of the great Renaissance glasshouses. Their wares remain world famous and are as exquisite as they were then.

IVAN AMATO

For FurTher ReAding: Chloe Zerwich, $A$ Short History of Glass (Harry N. Abrams, Publishers Inc., in association with the Corning Museum of Glass, New York, 1990); Ada Polak, Glass: Its Tradition and Its Makers (G.P Putnam's Sons, New York, 1975); websites: http: / www.muranoglass. com/history.html and http:/ / 194.20.231.1/ murano/muranoi.htm. 